\title{
Evaluation of Lubricating Properties of Diesel Based Fuels Micro Emulsified With Glycerin
}

\author{
Igor Micael Alves Uchôa ${ }^{a}$, Afonso Avelino Dantas Neto ${ }^{a}$, Erinéia da Silva Santos $^{a *}$, \\ Luiz Ferreira de Lima ${ }^{a}$ Eduardo Lins de Barros Neto ${ }^{a}$ \\ ${ }^{a}$ Universidade Federal do Rio Grande do Norte - UFRN, Campus Universitário, Lagoa Nova, CEP \\ 59072-970, Natal, RN, Brazil
}

Received: December 08, 2016; Revised: October 02, 2017; Accepted: November 10, 2017

\begin{abstract}
The mineral diesel oil sold in Brazil, due to environmental reasons; presents sulfur concentration of $10 \mathrm{ppm}$, which causes a deficiency of lubricity, since sulfur is one of the chemical species that gives a good lubricating characteristic. Poor lubricity affects performance and causes failure of engine parts. This study aimed to evaluate the use of glycerin as an antiwear additive by means of tribological tests of the mineral diesel S10 B7 and 10 formulations of diesel based fuels, micro emulsified with $0 \%$ (distilled water), $7.5 \%$ and $15 \%$ of glycerin solution. The formulations were subjected to lubricity tests on HFRR (Hight Frequency Reciprocating Rig) under hydrodynamic lubrication conditions, according to the ASTM D-6079 standard. The results showed that the increased concentration of glycerin added to diesel S10 B7 contributes to improved lubricity and wear reduction.
\end{abstract}

Keywords: Diesel S10 B7, Glycerin, Lubricity, Tribological Tests, Wear Reduction

\section{Introduction}

Diesel is a fossil fuel obtained from the distillation of petroleum, being used mainly in motors of automobiles, buses, trucks and large machines ${ }^{1,2,3}$. The wide use of this fuel has increased emissions of pollutant gases into the atmosphere such as $\mathrm{CO}_{\mathrm{x}}, \mathrm{NO}_{\mathrm{x}}, \mathrm{SO}_{\mathrm{x}}$ and soot ${ }^{4}$. These gases have an influence on the aggravation of the greenhouse effect, cause acid rain and a decrease in the quality of the air ${ }^{5}$.

To reduce $\mathrm{SO}_{\mathrm{x}}$ emissions in the atmosphere, sulfur concentration in Brazilian mineral diesel is currently limited to $10 \mathrm{ppm}$, according to CONAMA Resolution 403/20086. Low sulfur concentration in diesel is also required in the United States and Europe ${ }^{7}$.

This causes a decrease in lubricity, because in the treatment process a large part of the sulfur, oxygenated and nitrogen compounds are withdrawn ${ }^{8}$. Poor lubricity will affect engine performance, as in accelerated wear and insufficient engine power. It also shortens the lifespan of the engine ${ }^{9}$ and causes energy dissipation by friction and failure of engine parts such as fuel injectors and pumps ${ }^{8}$.

Currently, much research has been reported to increase lubricity of ultra-low sulfur diesel (ULSD). Important techniques like coatings, texturing ${ }^{10}$ and addition of antiwear agent can be mentioned. The addition of an antiwear agent may be the most effective way to solve the lubricant problems and recent researches have focused in carboxylic acids, amides, alcohols, ether and biodiesel like antiwear agents ${ }^{11}$. This polar chemical species when added to ULSD gives a good lubricant property to the fuels, because they adsorb on the

*e-mail: Erineia.ufcg@gmail.com friction surface to form the protective film ${ }^{12,13}$ that prevents the metal to metal contact, reduces wear under loads, and promotes the integrity of the injection system ${ }^{8}$.

The lubricity can be evaluated by ASTM D-6079 which is based on the analysis of the average scar diameter in the $\mathrm{x}$ and $y$ directions formed on the surface of the AISI 52100 steel ball of the tribological pair used in the HFRR ${ }^{14}$. Generally small scars mean a good lubricating condition. The maximum size, for a good lubricant condition, allowed by ASTM D $975-10$ is $520 \mu \mathrm{m}^{15}$ and by EN $590-10$ is $460 \mu \mathrm{m}^{16}$.

Muñoz et al. ${ }^{7}$ performed HFRR experiments and found that diesel with 50 ppm sulfur without lubricant additive creates a wear scar diameter (WSD) of approximately 600 $\mu \mathrm{m}$. However, when diesel is added with small percentages of $5 \%$ and $10 \%$ biodiesel, they verified that the wear diameter decreases with the increase of the content biodiesel in the diesel.

Mello et al. ${ }^{17}$ evaluated the tribological characteristics of 50,500 and $1800 \mathrm{ppm}$ sulfur diesel fuels and their mixtures with soybean biodiesel and sunflower biodiesel with mixtures of $5 \%, 20 \%$ and $100 \%$ by volume. The results showed that the wear and coefficient of friction (COF) increase with the reduction of the sulfur content in pure diesel. This effect is minimized by increasing the concentration of biodiesel in the mixture.

$\mathrm{Hu}$ et al. ${ }^{11}$ used tall oil fatty acid (TOFA) as antiwear agent to the ultra-low sulfur non-additive diesel and ultra-low sulfur additive diesel. When the content of TOFA antiwear agent increased from 0 to $500 \mu \mathrm{g} / \mathrm{g}$, the WSD of the nonadditive diesel decreased from initial $630 \mu \mathrm{m}$ to $250 \mu \mathrm{m}$, reducing by $60.3 \%$, the COF reduced by $95.7 \%$, from the initial 0.47 to 0.02 . When the amount of TOFA is $500 \mu \mathrm{g} / \mathrm{g}$ 
in the ultralow sulfur additive diesel, the COF is reduced by $74.3 \%$, from the initial number of 0.070 to 0.018 and the WSD diesel is reduced by $44.4 \%$, from the initial 390 $\mu \mathrm{m}$ to $217 \mu \mathrm{m}$.

Knothe and Steidley ${ }^{13}$ studied a many fatty compounds and the effects of blending compounds found in biodiesel on petro diesel lubricity. The tests were developed in HFRR and it was considered just WSD like parameter of lubricity. The fatty compounds have better lubrication than hydrocarbons due to the presence of $\mathrm{O}$ atoms which provide polarity to the molecule and consequently adhesion to the metal surface. Lubrication improves somewhat with chain length. The authors proposed a descending order of oxygenated parts that increase lubrication: $\left(\mathrm{COOH}>\mathrm{CHO}>\mathrm{OH}>\mathrm{COOCH}_{3}\right.$ $>\mathrm{C}=\mathrm{O}>\mathrm{C}-\mathrm{O}-\mathrm{C}$ ).

Sukjit et al. ${ }^{18}$ Investigated lubrication properties of various oxygenated compounds, carboxylic acid, aldehyde, alcohol, ketone, ester, and ether. The authors used HFRR to measure the lubricity. The functional moieties were found to be the factor that most significantly influenced the lubricity. The oxygenated compound with carboxyl group possesses the highest polarity and leads to the best lubricity and the mild abrasive wear. Ketone has the lowest lubricity, the dominating mechanisms in the case of 2-decanone are abrasive wear with corrosion.
The objective of this study is to investigate the lubricity of fuel formulations, diesel base and micro emulsionates containing glycerin in aqueous solution; where the concentration of surfactant, ratio between the surfactants and the concentration of glycerin solution was varied.

\section{Materials and Methods}

\subsection{Materials}

In this research, a common diesel commercialized in gas stations in Brazil with 10-ppm sulfur and 7 percent biodiesel (diesel S10 B7) was used. The surfactants used are composed by Alkyl-phenyl glycolic polyether with 4 and 6 ethylene oxide units provided by Oxiteno SA. The solutions of glycerin were prepared using distilled water and glycerin provided by Synth LTDA. Table 1 describes the composition and physical-chemical properties of surfactants and Table 2 describes the physical-chemical properties of diesel S10 B7 and glycerin.

\subsection{Formulation of micro emulsified fuels}

The fuels micro emulsified were developed following a statistical study of type $2^{3}$ with duplicate at the central point, so the independent variables studied were: concentration of surfactant, ratio between surfactants and concentration

Table 1. Composition and physical-chemical properties of surfactants.

\begin{tabular}{lcc}
\hline Properties & Surfactant R4 & Surfactant R6 \\
\hline Composition & $\begin{array}{c}\text { Nonylphenol ethoxylated 4EO (CAS } \\
9016-45-9):>98 \% \text { in weight } \\
\text { Alkyl-phenyl glycolic polyethers } \\
\text { Viscous, colorless liquid, practically } \\
\text { odorless }\end{array}$ & $\begin{array}{c}\text { Nonylphenol ethoxylated 6EO (CAS } \\
9016-45-9):>98 \% \text { in weight } \\
\text { Alkyl-phenyl glycolic polyethers } \\
\text { Viscous, colorless liquid, practically } \\
\text { odorless }\end{array}$ \\
Aspect & 8.9 & 10.9 \\
HLB & $<-10^{\circ} \mathrm{C}$ & $<-10^{\circ} \mathrm{C}$ \\
Fusion point & aproximatelly $240{ }^{\circ} \mathrm{C}$ & aproximatelly $245^{\circ} \mathrm{C}$ \\
Flash Point & $36-46{ }^{\circ} \mathrm{C}$ & $57-65^{\circ} \mathrm{C}$ \\
Cloud point & at $20^{\circ} \mathrm{C}:<0.001 \mathrm{kPa}$ & at $20^{\circ} \mathrm{C}:<0.001 \mathrm{kPa}$ \\
Steam pressure & at $25^{\circ} \mathrm{C}: 1020 \mathrm{~kg} / \mathrm{m}^{3}$ & at $25^{\circ} \mathrm{C}: 1040 \mathrm{~kg} / \mathrm{m}^{3}$ \\
Density & at $25^{\circ} \mathrm{C}: 200$ to $250 \mathrm{mPa} . \mathrm{s}$ & at $25^{\circ} \mathrm{C}: 200$ to $250 \mathrm{mPa} . \mathrm{s}$ \\
Viscosity & &
\end{tabular}

Table 2. Physical-chemical properties of diesel S10 B7 and glycerin.

\begin{tabular}{lcc}
\hline Properties & Diesel S10 B7 & Glycerin \\
\hline Aspect & Clean and free of impurities & Colorless to yellowish liquid \\
$\mathrm{pH}$ & Not applicable & $\sim 5$ \\
Boiling Point & $141{ }^{\circ} \mathrm{C}$ & $290{ }^{\circ} \mathrm{C}$ \\
Fusion Point & - & $17^{\circ} \mathrm{C}$ \\
Flash Point & $38{ }^{\circ} \mathrm{C}$ & $176{ }^{\circ} \mathrm{C}$ \\
Steam pressure & at $40{ }^{\circ} \mathrm{C}: 0.4 \mathrm{kPa}$ & at $20^{\circ} \mathrm{C}:<0.05 \mathrm{kPa}$ \\
Density & at $25^{\circ} \mathrm{C}: 820$ a $850 \mathrm{~kg} / \mathrm{m}^{3}$ & at $25^{\circ} \mathrm{C}: 1260 \mathrm{~kg} / \mathrm{m}^{3}$ \\
Viscosity & at $25^{\circ} \mathrm{C}: 0.527 \mathrm{cP}$ & at $25^{\circ} \mathrm{C}: 1.49 \mathrm{cP}$ \\
\hline
\end{tabular}


of the glycerin solution. The observed response was the mass concentration of the glycerin solution added to diesel S10 B7. Factorial design was used at three levels: low (-1), medium (0), and high (1). The values of levels are shown in the Table 3. All graphs and calculations of the effects were obtained with STATISTICA 7.0 software. All experiments were done in duplicate and the mean value was used as the experimental response.

Table 3. Factors and levels used in experimental design

\begin{tabular}{lccc}
\hline Level & $\begin{array}{c}\text { Surfactants } \\
\text { concentration } \\
(\mathbf{g} / \mathbf{1 0 0 m L} \\
\text { diesel) }\end{array}$ & $\begin{array}{c}\text { Surfactants } \\
\text { ratio (R4/ } \\
\mathbf{R 6})\end{array}$ & $\begin{array}{c}\text { Glycerin solution } \\
\text { concentration } \\
\mathbf{( \% )}\end{array}$ \\
\hline-1 & 5.5 & $1 / 1$ & 0 \\
0 & 8.25 & $3 / 2$ & 7.5 \\
1 & 11.0 & $2 / 1$ & 15 \\
\hline
\end{tabular}

Each micro emulsion systems was developed with samples of $100 \mathrm{~mL}$ of diesel S10 B7 in which were added the concentration and the ratio between the surfactants shown in Table 4. The systems were kept under mechanical stirring and titrated dropwise with distilled water (glycerin-free solution) and aqueous solutions of glycerin $(7.5 \%$ and $15 \%)$ to the turbidity point. The formulations after the agitation process acquire a transparent appearance, which is the evidence of the microemulsion formation ${ }^{19}$.

\subsection{Tribological study}

The tribological performance of diesel S10 B7 and formulated fuels were evaluated from HFRR tests following the ASTM D 6079 standard. The description of the characteristics of the tribological pair is shown in Table 5 . Both the ball and the disc are composed of AISI 52100 steel with composition shown in Table 6 . The tribological pair is subjected to a load of $1.96 \pm 0.01 \mathrm{~N}$, a frequency of $50 \pm$ $1 \mathrm{~Hz}$ and submerged in $2.0 \pm 0.2 \mathrm{~mL}$, over time of $75 \mathrm{~min}$. The temperature of the experiment was maintained at $60 \pm$ $2{ }^{\circ} \mathrm{C}$. Before the experiment, the tribological pairs (ball and disc) were cleaned by immersion in ultrasonic bath with isopropyl alcohol for 10 minutes and dried with hot air. All tribological experiments were repeated twice for each fuel.

\subsection{Surface analysis}

By ASTM standard D-6079 the scar diameter analysis is done as a mean of the length values in the $\mathrm{x}$ and $\mathrm{y}$ axis formed on the steel ball surface, measured in $\mu \mathrm{m}$. Length determination is performed after the HFRR test by using an optical microscope with magnification of 100 times. The lengths of the scars formed on the disks were determined by scanning electron microscopy (SEM) and the chemical analysis on worn surface was done with electron dispersive scanning (EDS).

\section{Results and Discussion}

\subsection{Formulations of micro emulsified fuels}

From analyzing the results of the glycerin micro emulsified fuels formulations shown in Table 4, it can be concluded that the highest mass concentration of the solution containing distilled water (glycerin-free solution) incorporated into the S10 B7 diesel occurred for the surfactants concentration of $11.0 \mathrm{~g} / 100 \mathrm{~mL}$ of diesel, and proportion of surfactants (R4/ R6) of $1 / 1$. However, for micro emulsion formulations with $15 \%$ glycerin, it occurred at the concentrations of surfactants of $11.0 \mathrm{~g} / 100 \mathrm{~mL}$ of diesel and proportion of surfactants (R4/ R6) of $1 / 1$ occurred. The higher concentration of surfactants

Table 4. Solubility of the micro emulsified fuels and their names.

\begin{tabular}{lcccc}
\hline Formulation & $\begin{array}{c}\text { Surfactants } \\
\text { concentration } \\
\text { (g/100mL diesel) }\end{array}$ & $\begin{array}{c}\text { Surfactants ratio (R4/ } \\
\text { R6) }\end{array}$ & $\begin{array}{c}\text { Glycerin solution } \\
\text { concentration (\%) }\end{array}$ & $\begin{array}{c}\text { Mass concentration } \\
\text { of glycerin solution in } \\
\text { diesel (g sol. glycerin } \\
\text { /g total) }\end{array}$ \\
\hline $\mathrm{S}_{5.5} \mathrm{R}_{1 / 1} \mathrm{G}_{0}$ & -1 & -1 & -1 & 0.0218 \\
$\mathrm{~S}_{11.0} \mathrm{R}_{1 / 1} \mathrm{G}_{0}$ & 1 & -1 & -1 & 0.1147 \\
$\mathrm{~S}_{5.5} \mathrm{R}_{2 / 1} \mathrm{G}_{0}$ & -1 & 1 & -1 & 0.0483 \\
$\mathrm{~S}_{11.0} \mathrm{R}_{2 / 1} \mathrm{G}_{0}$ & 1 & 1 & -1 & 0.0731 \\
$\mathrm{~S}_{5.5} \mathrm{R}_{1 / 1} \mathrm{G}_{15}$ & -1 & -1 & 1 & 0.0422 \\
$\mathrm{~S}_{11.0} \mathrm{R}_{1 / 1} \mathrm{G}_{15}$ & 1 & -1 & 1 & 0.0632 \\
$\mathrm{~S}_{5.5} \mathrm{R}_{2 / 1} \mathrm{G}_{15}$ & -1 & 1 & 1 & 0.0251 \\
$\mathrm{~S}_{11.0} \mathrm{R}_{2 / 1} \mathrm{G}_{15}$ & 1 & 1 & 1 & 0.0407 \\
$\mathrm{~S}_{8.25} \mathrm{R} 3 / 2 \mathrm{G}_{7.5}$ & 0 & 0 & 0 & 0.0586 \\
$\mathrm{~S}_{8.25} \mathrm{R}_{3 / 2} \mathrm{G}_{7.5}$ & 0 & 0 & 0 & 0.0600 \\
\hline
\end{tabular}

Legend: S (concentration of surfactant); R (ratio between surfactants); G means (concentration of the glycerin solution) where the subscribed corresponds to each factor value. 
Table 5. The physical characteristics of the tribological pair.

\begin{tabular}{lcc}
\hline & Ball & Disc \\
\hline Hardness $(\mathrm{HV})$ & $(570-750)$ & $(190-210)$ \\
Dimensions & Diameter $=6.0 \mathrm{~mm}$ & Diameter $=10.0 \mathrm{~mm}$ Thickness $=3.0 \mathrm{~mm}$ \\
Roughness Ra $(\mu \mathrm{m})$ & 0.05 & 0.02 \\
Steel Processing 52100 & Annealed & Tempered \\
\hline
\end{tabular}

Data provided by the manufacturer

Table 6. Chemical composition by weight (\% p.) from the AISI 52100 steel ball and disc.

\begin{tabular}{lccccccc}
\hline Fe & C & Mn & Cr & S & Si & Al & Ca \\
\hline Bal. & 0.900 & 0.413 & 1.567 & 0.127 & 0.546 & 0.105 & 0.154 \\
\hline
\end{tabular}

provides greater solubilization of the glycerin solution in the S10 B7 mineral diesel, keeping greater stability of the system.

These results show that the surfactants used promote the formation of water-in-oil microemulsions due to their ethoxylation, reflected in their BHL, 8.9 and 10.9. The presence of the glycerin in the aqueous phase ends up reducing the solubility of the aqueous phase in the formulations, i.e., glycerin is a polar organic compound and leads to the aqueous medium a less hydrophobic character reducing the aqueous phase solubility in the formulations. The thermodynamic stability of all microemulsions were confirmed by a visual analysis when systems were left standing for one year at room temperature. Non-phase separation (homogenous system) indicates the stability of the formulations.

Figure 1. shows the response surface graph where it's possible see the behavior of a pair of independent variables in mass concentration of the glycerin solution added to diesel S10 B7. According Figure 1 (A), (B) and (C), it is noted that the concentration of surfactant increases the solubility of the aqueous solution, while increasing the concentration of glycerol and R4/R6 ratios decrease the solubility. These phenomena occur in the case of the surfactant, where its increase in concentration increases the ability to micro emulsify water in the oil phase. In the case of glycerin, which is an organic polar compound, it decreases the interaction of the aqueous solution with the polar part of the surfactant, which reduces the solubility of the aqueous solution in the diesel phase. In the case of the R4/R6 ratio, the first surfactant has a lower affinity for water and the increase in its proportion promotes the reduction of the solubilizing capacity of the aqueous phase in the micro emulsion, as well.

The effects of the independent variables on the mineral diesel additives process discussed above can be summarized and clearly observed in the Pareto diagram shown in Figure 2. This was built for a 95\% confidence interval.

Analyzing the Pareto diagram, it is verifiable that all variables present a significant effect on the solubilization of the aqueous solution, with the biggest interference being the concentration of the surfactant, with a positive effect, whereas the glycerol concentration and the R4/R6 surfactant ratio have a negative effect.

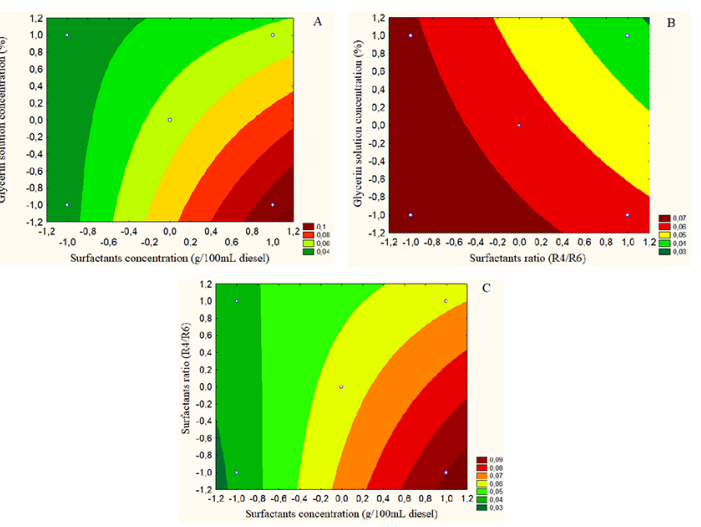

Figure 1. Response surface: (A) concentration of surfactant as a function of the concentration of glycerol solution, (B) proportion between surfactants as a function of the concentration of glycerol solution and (C) concentration of surfactant as a function of the ratio of surfactants.

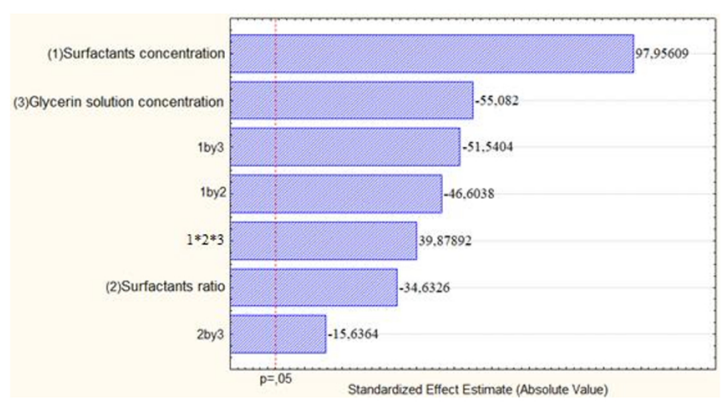

Figure 2. Pareto chart.

\subsection{Lubricity: percentage of film formation, coefficient of friction (COF) and wear scar diameter (WSD)}

Figures 3 and 4 show respectively the percentage of film formation and the coefficient of friction obtained during the tribological tests of the mineral diesel S10 B7 and the 10 formulated fuels. Analyzing Figure 3. it is possible to confirm that the percentage of lubricating film formation of the mineral diesel S10 B7 shows rapid growth and the value of $100 \%$ film is reached in 750 seconds. This value remains stable throughout the test. This behavior was verified in other 


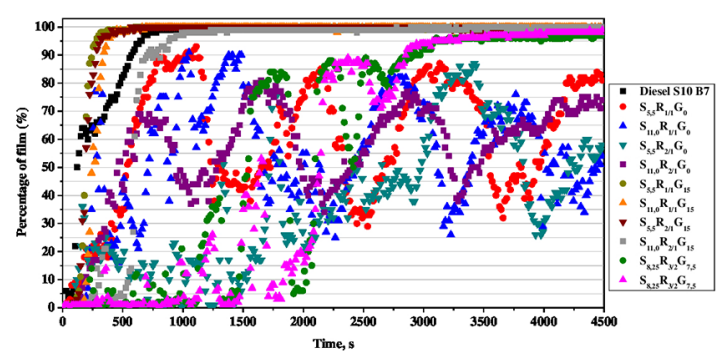

Figure 3. Percentage of lubricating film formation on the disc surface.

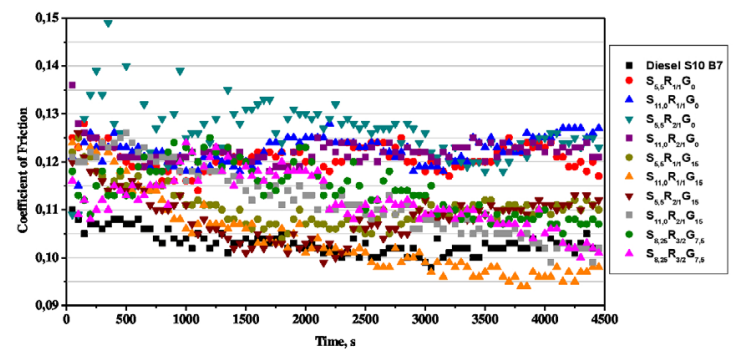

Figura 4. Coefficient of friction of the contact disc-ball lubricated.

studies, because despite the low concentration of sulfur ( 10 ppm), the addition of $7 \%$ biodiesel gives good lubricity ${ }^{8,12}$.

In the formulations with $0 \%$ of glycerin (distilled water), due to water do not present a lubricating characteristic ${ }^{20}$, the lubricating films are formed but can not remain on the surface of the discs and are broken, so the profiles were similar to each other with high instability in the formation of the films and reached peaks around $90 \%$ of film but did not keep this value this during the entire tests.

The addition of the $15 \%$ glycerol solution at any concentration in the mineral diesel improved the formation of the lubricant film since it was presented greater stability and a reduction in approximately 250 seconds for obtaining $100 \%$ lubricating film formation. One cause of increase of lubricity is due to the fact that the glycerin presents three polar groups of the type $\mathrm{OH}^{16}$. These groups provide better adsorption on the surface and consequently increase the efficiency in the metal coating and improves lubrication capacity, protecting the surfaces ${ }^{18}$.

In the formulations that were added $7.5 \%$ glycerin solution, an oscillating profile is noted up to 3000 seconds of test. From that time and on, the systems formed a stable film with values above $95 \%$. Thus the condition of $7.5 \%$ of glycerin is intermediate to $0 \%$ and $15 \%$ in the process of improving the lubricity property.

Additionally, these results show that the presence of distilled water in the formulations only destabilizes the surface film after its formation. This fact is related to the evaporation of water during the test causing the film to rupture, generating a sequential effect of formation and rupture of the lubricating film ${ }^{21}$. This phenomenon ends up being minimized by increasing the concentration of glycerin in the aqueous solution. Glycerin has a boiling point in the order of $290^{\circ} \mathrm{C}$ and the water/glycerin mixture has its boiling temperature increased, which decreases the evaporation effect by improving film stability, reaching better results than the S10 B7 diesel for formulations with 15\% glycerin. In formulations with $7.5 \%$ glycerin, as seen previously, the oscillating profile is due to higher evaporation of water during the first 3000 seconds of the test. After this time and with a greater amount of water evaporated from the system, the stabilization of the lubricating film is noticed.

The results presented in the study of the friction coefficient (COF) corroborate with the stability of the film, as it can be seen in Figure 4, the samples with higher content of glycerin in the aqueous solution have lower coefficients of friction, that is, diesel S10 B7. It is noteworthy that the viscosity measurements of the micro emulsion formulations were performed and the values were around $0.6 \mathrm{cP}$ indicating that the presence of glycerin in the formulation does not promote a significant change in this parameter, thus evidencing that the decrease of the evaporation is that interferes in this behavior. It is also worth noting that the presence of $\mathrm{OH}$ groups in glycerin also play an important role in the lubricity improvement ${ }^{16,18}$.

The lubricity characteristics for mineral diesel S10 B7 and the formulations developed can be analyzed by observing the size of the scars on the spheres used in the HFRR experiments. According to CEN EN 590 (2004) ${ }^{11}$, the maximum average wear value specified is $460 \mu \mathrm{m}$ (at 60 $\left.{ }^{\circ} \mathrm{C}\right)$. For ASTM D-975 $(2010)^{10}$, the maximum acceptable value is $520 \mu \mathrm{m}\left(60^{\circ} \mathrm{C}\right)$.

Figure 5 shows the WSD values analyzed by light microscopy, with magnification of 100x. Based on these results, the mineral diesel $\mathrm{S} 10 \mathrm{~B} 7$ presented average value of $175 \mu \mathrm{m}$. Values that are compatible with international standards. The S10 B 7 mineral diesel formulations with $0 \%$ glycerin solution (distilled water) resulted in WSD values greater than $255 \mu \mathrm{m}$ which causes greater wear between the metal surfaces. The values of WSD for formulations with glycerin $15 \%$ presented lower scar measurements than the one obtained for the mineral diesel S10 B7. The values varied from a minimum of $83 \mu \mathrm{m}$ to $113 \mu \mathrm{m}$, evidencing that the addition of glycerin in this condition promoted an increase in the lubricating property of the mineral diesel, evidenced by the decreased wear and, consequently, greater protection of the metallic surface. The values of WSD for the formulations with $7.5 \%$ of glycerin present intermediate values to those obtained with the other fuels.

The WSD results of the formulations studied corroborate with the results obtained from the percentage coverage and friction coefficient, showing that glycerin is an additive that combined with water in micro emulsion systems can have good lubricity results. 


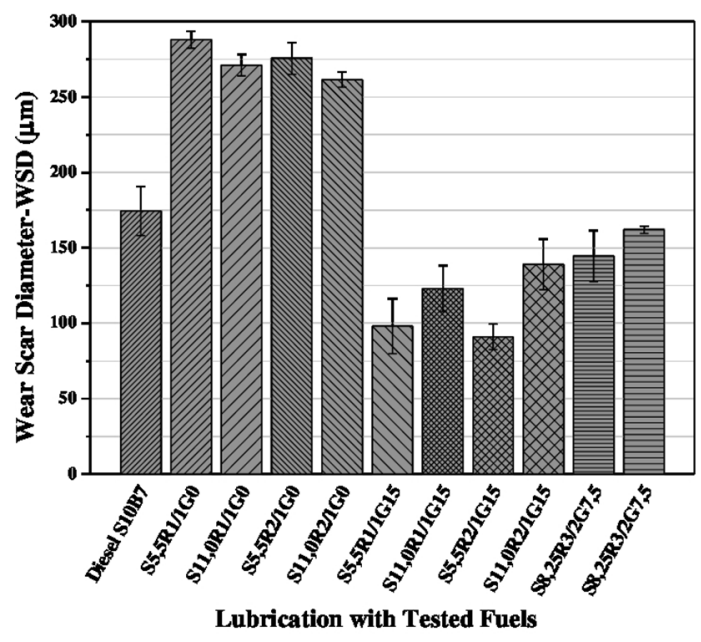

Figura 5. WSD of the balls used for the HFRR tests.

\subsection{Worn steel disc surface analysis}

The morphologies and chemical elements distribution of the worn disc surfaces were analyzed by SEM equipped with EDS. The images of worn discs are shown in Figure 6. The first column show full scar and length value and the second column show the center of scar. The dotted circle represents where EDS was made. From the micrographs obtained for the Diesel S10 B7, a small wear is noticed; this is due to the efficiency of the addition of $7 \%$ biodiesel (B7), which is responsible for partially restoring the lubrication capacity of the diesel fuel that presents low levels of sulfur'.

Comparing the effect of additives on the diesel S10 B7 with the solution of $0 \%$ glycerin, we have the highest values of bedsores. This occurs because water does not have a lubricating character in the formulated systems and also because of the evaporation factor because when the lubricating film breaks the metal-metal contact is more pronounced which generates a high scars.

For all fuels formulated with $15 \%$ glycerin solution, the sizes of the scars were the smallest. These formulations presented higher lubricity, contributing to a lower abrasive wear. According to these results, the low values in the wear are because the three polar groups of the type $\mathrm{OH}$ present in glycerin give it a better adsorption on the surface, consequently increasing the efficiency in the metal coating and improves lubrication capacity, protecting the surfaces ${ }^{17}$. Additionally the minimized evaporation effect for these formulations also contribute to generate these smaller scars.

Compared with the $\mathrm{S}_{8.25} \mathrm{R}_{3 / 2} \mathrm{G}_{7.5}$ formulation, performed in duplicate, it is noted that the scar lengths have values between the scars sizes of the formulations added with $15 \%$ glycerin (minimum values) and the formulations added with glycerin $0 \%$ (maximum values). It is also observed that formulations containing high glycerin concentration have a smaller scar size than mineral diesel S10 B7. This occurs due to boiling temperature increased, which decreases the

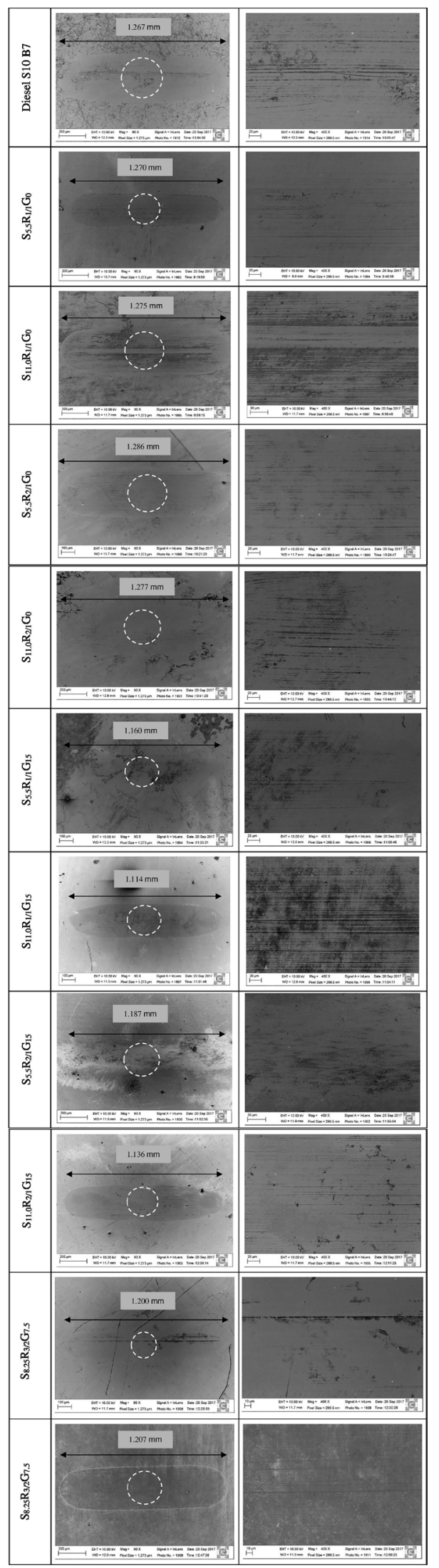

Figure 6. SEM of the discs worn surfaces after HFRR test lubricated with S10 B7 diesel and formulations. 


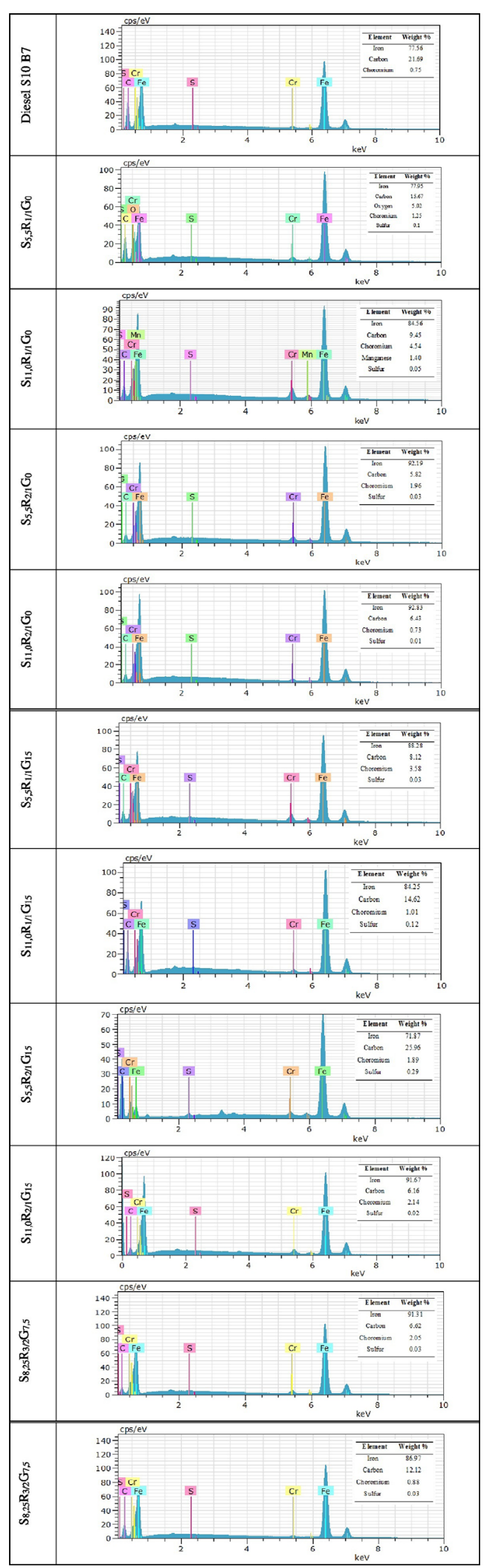

Figure 7. EDS analysis of worn surface of steel discs. evaporation effect by improving film stability. The high amount of glycerin in the system means a bigger amount of hydroxyl, consequently, high efficiency of adsorption and prevents wear.

In all images SEM there are abrasive signals and it seems to be the main wear mechanism. The abrasion wear is noted by prow formation and plowing on disc specimens. Probably the difference between hardness of the disk/ball and debris formation and its rolling between sliding surfaces contributes to this mechanism of wear.

Analyzing the SEM images, some dark spots can be seen in the disk wear range, especially when the percentage of glycerin is increased, which may suggest an oxidative process during the tests. However an EDS analysis, depicted in Figure 7, showed similar profiles for all disks and that such black residues are carbon. The formation of carbon is the result of the heat generated during wear between the metal surfaces and the diesel. This result was also confirmed in other studies using HFRR for determination of diesel lubricity ${ }^{8,22}$.

\section{Conclusions}

On the basis of results presented, it can be concluded that:

- $\quad$ Despite the low sulfur concentration, the S10 B7 diesel sold in Brazil has good lubricity.

- All formulated microemulsions have met international wear specifications.

- The oscillation of the percentage of film formation showed that during the tests the film forms and ruptures, due to water evaporation, and its regeneration is due to the great mobility that the micro emulsion systems have to migrate from the sinus of the solution to the metallic surface.

- The increase of glycerine in the mineral diesel is linked to the increase in the lubricity of the system due to the better adhesion of the fuel to the steel disc surface promoted by the polar species present in the system and the reduction of the evaporation with consequent maintenance of the lubricating film.

- $\quad$ SEM analysis shows that the predominant mechanism of wear on disc surfaces was abrasion and EDS analyzes did not show an oxidative process.

\section{References}

1. Liu H, Wang Z, Zhang J, Wang J, Shuai S. Study on combustion and emission characteristics of Polyoxymethylene Dimethyl Ethers/diesel blends in light-duty and heavy-duty diesel engines. Applied Energy. 2017;185(Pt 2):1393-1402. DOI: 10.1016/j. apenergy.2015.10.183

2. Geng P, Tan Q, Zhang C, Wei L, He X, Cao E, et al. Experimental investigation on NOx and green house gas emissions from a marine auxiliary diesel engine using ultralow sulfur light fuel. 
Science of the Total Environment. 2016;572:467-475. DOI: 10.1016/j.scitotenv.2016.08.047

3. Brazil. Ministry of Mines and Energy. BEM 2016. Balanço energético nacional. Available from: $<$ https://ben.epe.gov. br/downloads/Relatorio_Final_BEN_2016.pdf $>$. Access in: 20/11/2016.

4. Tan YH, Abdullah MO, Nolasco-Hipolito CN, Zauzi NSA, Abdullah GW. Engine performance and emissions characteristics of a diesel engine fueled with diesel-biodiesel-bioethanol emulsions. Energy Conversion and Management. 2017;132:5456. DOI: 10.1016/j.enconman.2016.11.013

5. Damm CJ, Lucas D, Sawyer RF, Koshland CP. Characterization of diesel particulate matter with excimer laser fragmentation fluorescence spectroscopy. Proceedings of the Combustion Institute. 2002;29(2):2767-2774. DOI: 10.1016/S1540-7489(02)80337-6

6. Brazil. Ministry of the Environment. Conselho Nacional do Meio Ambiente (CONAMA). Resolução CONAMA No 403/2008. Available from: $<$ http://www.mma.gov.br/port/conama/legiabre. cfm?codlegi $=591>$. Access in: 20/11/2017.

7. Muñoz M, Moreno F, Monné C, Morea J, Terradillos J. Biodiesel improves lubricity of new low sulphur diesel fuels. Renewable Energy. 2011;36(11):2918-2924. DOI: 10.1016/j. renene.2011.04.007

8. Farias ACM, Medeiros JTN, Alves SM. Micro and nanometric wear evaluation of metal discs used on determination of biodiesel fuel lubricity. Materials Research. 2014;17(Suppl 1):89-99. DOI: 10.1590/S1516-14392014005000101

9. Xu X, Sun S, Wang P, Lei A, Peng G. Study on Tribology Performance of Diesel Engine Oil Using SRV4 Tribometer. Tribology Online. 2015;10(2):172-176. DOI: 10.2474/trol.10.172

10. Arslan A, Masjuki HH, Varman M, Kalam MA, Quazi MM, Al Mahmud KA, et al. Effects of texture diameter and depth on the tribological performance of DLC coating under lubricated sliding condition. Applied Surface Science. 2015;356:11351149. DOI: $10.1016 /$ j.apsusc.2015.08.194

11. Hu Z, Zhang L, Li Y. Investigation of tall oil fatty acid as antiwear agent to improve the lubricity of ultra-low sulfur diesels. Tribology International. 2017;114:57-64. DOI: 10.1016/j. triboint.2017.04.016
12. Nicolau A, Lutckmeier CV, Samios D, Gutterres M, Piatnick CMS. The relation between lubricity and electrical properties of low sulfur diesel and diesel/biodiesel blends. Fuel. 2014;117(Pt A):26-32. DOI: 10.1016/j.fuel.2013.09.026

13. Knothe G, Steidley KR. Lubricity of Components of Biodiesel and Petrodiesel: The Origin of Biodiesel Lubricity. Energy \& Fuels. 2005;19(3):1192-1200. DOI: 10.1021/ef049684c

14. ASTM International. ASTM D 6079-04 - Standard Test Method for Evaluating Lubricity of Diesel Fuels by the High-Frequency Reciprocating Rig (HFRR). West Conshohocken: ASTM International; 2004.

15. ASTM International. ASTM D975-10 - Standard Specification for Diesel Fuel Oils. West Conshohocken: ASTM International; 2010.

16. European Committee for Standardization. EN-590: Automotive Fuels - Diesel-Requirements and test methods. Brussels: European Committee for Standardization; 2009.

17. Silva e Mello V, Farias ACM, Souza ERV, Oliveira MVA, Alves SM. Effect of desulfurization of diesel and its blends with biodiesel on metallic contact. Materials Research. 2014;17(Suppl 1):82-88. DOI: $10.1590 / 1516-1439.222313$

18. Sukjit E, Poapongsakorn P, Dearn KD, Lapuerta M, SánchezValdepeñas J. Investigation of the lubrication properties and tribological mechanisms of oxygenated compounds. Wear. 2017;376-377(PtA):836-842. DOI: 10.1016/j.wear.2017.02.007

19. Cheraghian G. Effects of nanoparticles on wettability: A review on applications of nanotechnology in the enhanced Oil recovery. International Journal of Nano Dimension. 2015;6(5):443-452. DOI: $10.7508 /$ ijnd.2015.05.001

20. Hudedagaddi CB, Raghav AG, Tortora AM, Veeregowda DH. Water molecules influence the lubricity of greases and fuel. Wear. 2017;376-377(PtA):831-835. DOI: 10.1016/j.wear.2017.02.002

21. Kuszewski H, Jaworski A, Ustrzycki A. Lubricity of ethanol-diesel blends - Study with the HFRR method. Fuel. 2017;208:491498. DOI: 10.1016/j.fuel.2017.07.046

22. Sukjit E, Herreros JM, Dearn KD, García-Contreras R, Tsolakis A. The effect of the addition of individual methyl esters on the combustion and emissions of ethanol and butanol-diesel blends. Energy. 2012;42(1):364-374. DOI: 10.1016/j.energy.2012.03.041 